\title{
Invisible Children, Dying to Save Others: A Discussion of Three Fatal Child Abuse Cases and the Prevention of Future Deaths
}

\author{
Janice Sim*
}

\begin{abstract}
This article discusses three fatal child abuse cases (two from the United Kingdom and one from Australia). Using an interactionist framework, it identifies two critical signs - the 'invisibility' of the child and certain dysfunctional parent representations - as the precursors to death in these cases. Reviewing the child death inquiry findings, it argues that acknowledging these critical indicators of risk has significant implications for preventing death in similar cases where child protection workers know the child in question.
\end{abstract}

Keywords: child abuse - child death inquiry - scapegoating - child protection interactionism - United Kingdom - Australia

\section{Introduction}

[T]he child protection system contains an inherent bias against intervention anyway. If we wish to change that, then we must confront the social costs. If we do not consider that these costs are worth paying, then we must frankly acknowledge the human implications, that some children will die to preserve the freedom of others (Dingwall 1986:503).

The resilience and pitfalls of the United Kingdom's ('UK') and Australia's child protection systems were tested by the deaths of Daniel Pelka in 2012 (UK), Peter Connelly (Baby P) in 2007 (UK), and 'Ebony' (who cannot be named for legal reasons) in New South Wales ('NSW') in 2007. All three children died as a result of unspeakable abuse and neglect at the hands of their parents.

This article focuses on these three prominent fatal child abuse cases, drawing on observations from three child death inquiry reports into the deaths, to put forth two main arguments. First, there were certain precursors to the deaths, which, if noticed by the authorities (police,

Sessional Academic, Griffith Law School (Gold Coast Campus), Parklands Drive, Southport Qld 4215

Australia. Email: j.sim@griffith.edu.au. The themes in this article are based on the author's PhD thesis. The author is grateful to Eileen Baldry and Edwin Bikundo for their helpful comments. 
medical and social workers), would have saved the children's lives. It discusses two critical signs - the lack of child visibility and dysfunctional parent representations - that the authorities interacting with the families in these cases had missed. It argues that these indicators of risk obfuscated risks of harm to the child from the authorities. Even though none of these arguments are new, the article offers a different perspective to understanding the missed signs. There may be little to learn from these deaths since, in the past 30 years, the reasons identified for such deaths remain remarkably similar and difficult to change despite a range of legislative, police and practice changes. However, it is hoped that revisiting the same issues with a fresh lens invites practitioners to re-evaluate their approaches in practice.

Second, the article discusses the practice of scapegoating in child protection. Scapegoating has become a pervasive and persistent culture routinely interwoven into child protection practice (Ruch et al 2014). However, not all children who have suffered abuse and neglect become an issue of national concern (Jones 2014). The focus on the issue of scapegoating is for the preventative front. The argument is that, rather than continuing in a culture of individual blame, society must move to a culture of prevention by going beyond paying lip service to human deficiencies towards actual preventative strategies, such as early intervention and community child abuse prevention. Only in this way can the long road towards ensuring a safe outcome for all children at risk begin.

As Dingwall's quote (above) drily points out, no human system is infallible and, also, permanent, unsolicited and pervasive surveillance of private behaviour is untenable in a liberal society. Even though he made this statement 28 years ago, it may be that this remains the Achilles heel in child protection work. Western society has held onto the right of parents to discipline their children, respecting the domain of the family as private, thus contributing to the overall reluctance of public intrusion into private spaces (Donzelot 1979). Although child protection laws have attempted to navigate the delicate division between public and private lives (Rose 1987:62-3, 66-7), the gulf and tension between their theoretical aim of keeping children safe and the practical realities of this is exposed when deaths such as those discussed in this article occur. With an increasing focus in the legislation on children's safety and welfare (Reder et al 1993:16-17), monitoring families at risk is left to child protection workers who are also tasked with the challenge of assessing risks of child endangerment. This difficulty is compounded by the highly disturbing nature of social work practice (Harvey and Henderson 2014) when dealing with both parent and child at the same time. To oversimplify this dilemma, Jones (2014) frames the question as: why were the authorities 'blind' to what was actually going on? While this question remains largely unanswered, the article attempts an interactionist contextualisation of the critical signs of child endangerment.

\section{Child protection in context: An interactionist perspective}

Goffman (1959) theorises that individuals are comparable to social actors, who play various roles on various stages before an audience, presenting and cultivating a particular public facade, depending each time on what each stage demands. Goffman is essentially writing about a multilayered presentation of the individual in everyday life in various social contexts. Goffman's sociological analysis reinterprets the layered nature of filicide perpetrators. The parent perpetrators, as will be seen, present and represent themselves differently to different people, particularly to the police, social and health workers. Such a multifaceted quality challenges frontline social workers dealing with shades of human complexity every day (Cooper and Whittaker 2014). Munro (2011) points out that evidence-based practice that informs decision-making in risk assessment assists to produce a more complete picture, 
particularly of the layered context of violence within the family. The Serious Case Review Re Daniel Pelka ('Pelka Report') (Lock 2013) too, in its conclusion, recommends the need to return to evidence-based practice. This, however, it is argued, must be balanced with an understanding of the 'social actor'.

There are myriad theories in the field of child protection attempting to explain fatal child abuse (Tilbury et al 2007). No one theory can fully explain the phenomena - of faulty parental representations, the invisible child and the unseeing health worker - discussed in this article. Nor is the article postulating these cases as representative of all fatal child abuse. An interactionist approach, proposed here, draws together disparate sociological theories to suggest an understanding of the interactions that produce the particular conditions of endangerment seen in these cases. Although interactional theory has been criticised as failing to adequately explain the nature and directionality of interactions (Corby 2000), what is suggested in this article is the need to build a fuller picture with an interactional understanding of these critical signs in conjunction with the use of existing evidence-based practices. The core interactional element central in the two critical signs of child endangerment is the issue of representation.

Representation, for our purposes, is defined as a depiction of an idea or message in the form of a visual object or text - written or auditory - that can be analysed and read for meaning (Goodwin and Finkelstein 2005:163, 165). For Pollock (1988:6), representation stresses something refashioned, coded in rhetorical, textual or pictorial terms, quite distinct from its social existence. In other words, representation possesses the power to redefine and restructure a way of thinking, acting and even ordering in society. In this context, it may be said that when parents interact with the authorities in a particular way, they adopt a particular representation that could end up guiding subsequent interactions (Munro 1996:800-1). In practice, the ability to ascertain the nature of parent representations concerning the child's injuries is paramount when attempting to determine the extent and seriousness of his or her risk(s) of harm.

In child protection, the concept of representation views knowledge as symbolic and relativist, since all knowledge acquired by the social or health worker is not objective or absolute truth, but is positioned, political and partial (D’Cruz 2004). Viewing the parent through such a fractured lens (D'Cruz 2001), health and social workers are sometimes 'blind' to the underlying and impending threat of violence to the child. Goffman (1961) elucidates that stigmatised persons try to assuage the unease they see in others by acting as 'normal' as possible. In the cases, the parents did not satisfy the typical profile of the 'neglectful parent' or 'dangerous parent', even in the face of damning evidence of abuse. The behaviour of the parents is nothing less than 'normal' when interacting with the authorities and, arguably, such a representation allowed the parent perpetrator to elude detection; hence, the ongoing violence could continue.

\section{The place of child death reviews}

The faith in using operational practice to identify child endangerment risks is maintained through preventative groundwork such as that undertaken by the child death review or inquiry (Reder et al 1993:18). The belief that lessons can be learnt to prevent future deaths underpins every child death review (Australian Institute of Family Studies 2014). In NSW, the Children and Young Persons (Care and Protection) Act 1998 (NSW) ('CYPA') mandates state intervention where the safety of the child is compromised. It assumes child endangerment is foreseeable. Forward-looking laws such as the CYPA (as opposed to retroactive laws, such 
as the criminal law) and the Children Act 1989 (UK) aim to achieve prevention through risk assessment and early intervention (Morgan and Yeung 2009:5-6). However, it is clear that these laws did not provide the means to protect the children in these cases.

These deaths have prompted several inquiries to strengthen the child protection system. The Protection of Children in England (March 2009) (Laming Report), the two Serious Case Reviews into Peter Connelly's death (November 2008a, November 2008b, March 2009) ('Connelly Reports'), the Pelka Report, and the NSW Ombudsman report (2009) ('Ebony Report') into Ebony's death, have emerged from these cases. They all point to the need to build a better platform for multi-agency support and interagency communication. From this perspective, the reports' findings are comparable. Ironically, this echoes Dingwall's (1986:489) critique years earlier, of inquiry findings being repetitive. Even as child death reviews guide policy and practice reform, these processes are often also retroactive and, arguably, ritualised.

As Cooper and Whittaker (2014:261) point out, the 'inquiry process itself, culminating in the publication of the report, might constitute an unrecognised process of public mourning'. Inquiries' preoccupations with reconstructing events and missed opportunities are no more than mere formalities to represent societal inability to grapple with the loss of a child's life. There are other children who have died similar deaths but are never represented in a report or child death review (Cooper and Whittaker 2014). This can only mean that cases such as these (Connelly, Pelka and Ebony) represent countless more. Going back to Goffman's interactionist treatise, they represent the presentation of parents and children in everyday life. As such, the character of repetitiveness of inquiry outcomes is not only about repeated plugging of the gaps in policy reform; rather, it is symbolic of an underlying need to process public grief and blame (Reder and Duncan 1993:18).

The Connelly and Pelka Reports make clear that professional focus should be on the child. In addition, the Pelka Report calls for parent representations to be challenged and balanced against objective information (Pelka Report 2013:72 [15.3]). This recognition stresses the critical role parent representations have when child protection workers interacting with the family make decisions on subsequent interventions. As will be seen, parent representations can sometimes divert attention away from the child. The significance of this pronouncement, while not new, cannot be overemphasised. At the same time, the finding of this child death review demonstrates that its place in the system is not diminished. The continuing process of engaging with issues of repetition, responsibility and grief not only guides policy and institutional reform, but also, from an interactionist perspective, it is a deeply symbolic emblem of public mourning.

\section{Background: The children}

In the following three cases, the children had been known to child protection services. Their parents had interactions with the police, support and medical services and child protection workers. The children's injuries and absences from public spaces such as schools were explained away by the parents. In spite of the varying concerns held by community members for the safety of these children, child protection workers did not question the veracity of the parents' explanations.

Daniel Pelka was four years and eight months old when he died of physical assault and gross neglect amounting to torture at the hands of his parents. He grew up and suffered in an environment of secrecy (Pelka Report 2013:33 [5.13]), abuse, domestic violence (Morris 
2013), residential instability and multiple police, medical and social work interventions that were dysfunctional with regard to his safety (Pelka Report 2013:52 [6.59], 13 [5.4]; Harris 2005:38). The family moved houses at least five times in a space of four years (Pelka Report 2013). The school he attended noticed his injuries and poor attendance, but these concerns were not acted upon effectively (Pelka Report 2013:54-7). At the time of death, he was malnourished and dehydrated, with a total of 40 injuries (Pelka Report 2013:29 [4.87]).

Peter Connelly was 17 months old when he died of physical assault at the hands of his carers (his mother, her boyfriend and his brother). He was on the child protection register nine months after his birth but was returned to his mother's care five weeks after going onto the register (Jones 2008). Four days before he died, his mother deliberately smeared him with chocolate to conceal his bruises from a social worker (Jones 2008; Anthony 2009). At the time of death, he suffered 'more than 50 injuries' and had been seen 'no fewer than 60 times' by health and social workers (Jones 2008; Campbell et al 2008).

Ebony was autistic and seven years and seven months old when she died of chronic starvation and gross neglect at the hands of her parents (Ebony Report 2008:1). There were nine risk-of-harm reports made by community members and state agencies (Departments of Education and Training and Ageing Disability and Home Care) in the two years before her death. These reports centred on the filthy state of the family's home, domestic violence and Ebony being locked away by her parents (Ebony Report 2009:5, 12). The older children were sighted by a NSW Department of Community Services ('DOCS') caseworker, but not Ebony. The last person from the outside to see Ebony was the removalist who reported that she was 'sitting down ... unusually skinny' ( $R v B W \& S W$ (No 3) at [32]). A television technician noticed her room was closed and a rope tied between two door handles, preventing the opening of the door from inside her room ( $R \vee B W \& S W$ (No 3) at [35]). At death, she weighed three times less than expected. Her body was compared to 'a holocaust victim' (Kent 2009; Ryan 2014; Cummings 2009). The state of her lungs suggested no contact with the outdoors for months ( $R \vee B W \& S W(N o$ 3) at [39]-[44]).

The following discussion analyses two important, yet remarkably un-novel, observations that have emerged from these children's deaths. First, child protection workers in their engagement with the family did not properly sight the children, even though the children were often the subjects of these interactions. Second, child protection workers in their interactions with the parent(s) did not detect that parental representations about the children's condition and injuries were in fact false and misleading. None of these observations are new. This article applies an interactionist lens to these two critical indicators of child endangerment.

\section{Key report observations}

\section{Silent and invisible}

At times, Daniel appeared to have been 'invisible' as a needy child against the backdrop of his mother's controlling behaviour. His poor language skills and isolated situation meant that there was often a lack of a child focus to interventions by professionals (Pelka Report 2013:6).

In these cases, the most critical period, brief or prolonged, foreshadowing the children's deaths is when the child becomes silent (is not heard) and 'invisible' (is not seen). 'Invisibility' can happen in two ways: physically, as a result of being imprisoned, such as in Ebony's case; and/or metaphorically, in a situation where the child is physically present but 
the presence is somehow subsumed into the background of activities, such as happened to Daniel Pelka.

Daniel was sometimes physically confined in a 'bare box room' ( $R v$ Mariusz Krezolek and Magdelena Luczak at 2) to give his parents ‘some peace’ (Dolan 2013). Ebony was imprisoned in a room without windows for months. As a result of the sheer intensity and frequency of wilful abuse and neglect by Ebony's parents, her chronic starvation and imprisonment paradigmatically parallels the destruction of an individual in a concentration camp (Shengold 1997:97). At death, both children were compared to concentration camp victims (Dolan 2013; Keene 2009). The juxtaposition of the home and the camp is poignant, in that the violence against the children within these spaces, both in reality and symbolically, was invisible to, and hidden from, the outside world. The conflating symbols of 'home' and 'camp' speak volumes of the territorial stronghold of power and ownership exerted by the parents on the children. The children were relegated to an almost non-existent status. Their imprisonment added a layer of invisibility to the violence that was happening under the very eyes of those who were meant to protect them from harm. And although Daniel was occasionally 'seen', it would appear that his presence was markedly subsumed into the background of ongoing activities (medical, school, social work visits and family relocations).

The 'invisibility' of Daniel was compounded by the fact that he was attending school (albeit not regularly) where his injuries were noted and also seen by a paediatrician three weeks before he died. Despite that, months of 'appalling cruelty' ( $R v$ Mariusz Krezolek and Magdelena Luczak at 1) to Daniel went unnoticed. When Daniel was 'seen', his voice was rarely heard as he spoke little English (Pelka Report 2013:71 [14.9]; Holt 2013). If their 'invisible' statuses were not already disturbing, the fact that the professionals engaged in all of these three cases played a role in exacerbating the continuation of the ongoing violence is unquestionably alarming. It may be argued that the ineffective, and dysfunctional, interventions in both cases rendered yet another layer of invisibility to the children.

The 'invisibility' of the children meant that the interventions lacked child focus (Connelly Reports 2008b:6, 2009:33 [3.8.6]). This was noted in all the reports (Laming Report 2009:22; Pelka Report 2013:70 [14.5]; Ebony Report 2009:54; Connelly Reports 2009:40 [3.10.5]). The result of the children being 'unseen' is assessment delay, which also implied a general lack of belief in or complete ignorance of the children's injuries; authorities looked but did not see. Clearly and critically, this is an issue of which professionals interacting with families need to be mindful.

Baby Peter was not as 'invisible' because he was seen numerous times by professionals. He was at the centre of a multi-agency conference, which decided to allow his mother to resume care (Jones 2008). His death was as a result of delayed or untimely meetings (Connelly Reports 2008b:63-4), which, in turn, impacted on the failure to apprehend the mother's dysfunctional representations. Additionally, the mother's deliberate concealment of the violence towards Peter was enabled by the invisibility of the other two perpetrators (Connelly Reports 2008b:7, 2008b:51) who, child protection workers and police did not know, were living in the same house. This means that many of his mother's explanations for his injuries and her version of events were not rigorously interrogated against objective evidence (Connelly Reports 2008b:51, 2009c:39). Further, the acceptance of the mother's versions by caseworkers evidences their disconnection with what was actually going on. The result of unchallenged representations that were in fact dysfunctional in the context of ongoing intervention resulted in a deliberate concealment of violence from the authorities.

This next section unpeels the layers of interactional representation. In particular, it focuses on parent representations presented in the three cases - specifically, the representation of the 
caring parent. This representation is argued to be an indicator of risk in fatal child abuse, especially where there are existing outstanding concerns for the safety of children known to child protection services.

\section{Dysfunctional parent representations}

The second observable feature in these cases is the absence of timely intervention in ascertaining that parental versions that were at first believed to be true turned out to be inaccurate. This critical stage is significant because, had the representations been identified as dysfunctional (in that they were intended to mislead and conceal), the intervening efforts may have been redirected to prevent further escalation of violence.

In the three cases, the representation of the 'caring' parent was presented to the police, social and health workers with the intention of concealing the ongoing abuse. Ironically, the perpetrators were able to do this because they attributed the cause of the injuries, or 'mishaps', to the victim. In Peter's case, his mother wore 'an appearance of cooperation' when Peter was sick and when she sought help (Jones 2008). Such an appearance of compliance misled and misguided professionals' interactions with the family (Connelly Reports 2008a:95-6). Peter's mother also blamed the sustained injuries on Peter's errant behaviour of 'head banging' (Connelly Reports 2009:45, 64).

In Daniel's case, the Pelka Report observed that Daniel's mother was 'generally viewed as a caring mother' and 'adequate parent' by the school (Pelka Report 2013:54 [7.1]), although the teachers expressed concern for Daniel's 'excessive' eating habit and weight loss. Interestingly, the schools noticed Ebony's and Daniel's apparent weight loss and poor school attendances (Ebony Report 2009:4; Pelka Report 2013:5). Yet these were not registered as a cause for concern in terms of child safety. Daniel's mother also blamed Daniel for his outward show of bad behaviour (Pelka Report 2013:24-6). In Ebony's case, her parents did not permit caseworkers to see her (Ebony Report 2009:3-4, 13-14). The reasons given by her father for her absence were sleeping, being home schooled and autism (Ebony Report 2009:13, 41).

All three children were deliberately 'hidden' in various ways by their parents to prevent social workers from sighting them. The web of lies the parents spun around the children extended to their siblings who, no doubt, acted according to their parents' instructions $(R v$ Mariusz Krezolek and Magdelena Luczak at 3; Pelka Report 2013:6). The Court in Daniel's case condemned the gravity of these falsely conjured representations as a construction of 'a careful and wholly untruthful account that Daniel had a serious eating disorder and learning difficulties', which was 'deliberately designed to prevent interference by school, medical and welfare personnel, and to perpetuate the brutality being meted out to him' ( $R v$ Mariusz Krezolek and Magdelena Luczak at 3). The insidious nature of these parent representations meant that intervening efforts were misdirected towards the search for medical and behavioural solutions for the children. The recognition of dysfunctional representation to misguide is significant, because it completely changes the way risks of child endangerment are currently understood.

As a potential indicator of risk, dysfunctional representations are potentially harder to identify because they mask the context of the abuse and injuries, which are reframed by the perpetrators as the failings of the victims. Compared to usual risk factors, such as mental illness, prior abuse, and lack of social support (Wilczynski 1995:193), representation is an evolving and interactional phenomenon. As Wilczynski (1995:218) points out, risk factors in filicide (including fatal child abuse) cannot be attributed to one individual, social, psychiatric or situational factor. Instead, risk assessors must consider the interaction of risk factors (Reder and Duncan 1993:125). These cases show that dysfunctional representation is a key 
interactive factor that allows potentially serious risks to the child to be downplayed or reconstructed by the perpetrator in favour of other considerations.

It is not difficult to see that the (false) belief that the injuries were not serious was largely generated by the parents' representation (namely, the appearance of cooperation) with the intervening professionals. Any safety concerns were massaged by the parents and represented as the children's behavioural weaknesses. As Reder and Duncan (2000b:130) point out, social and medical professionals need to be vigilant to parental explanations of injuries. Rather than viewing such parent representations as 'caring' or 'cooperative', professionals need to also treat them as 'covert warnings' (Reder and Duncan 2000b:130), because mistimed and misplaced intervention, as these cases prove, can be fatal. These red flags - the children's 'invisibility' and untimely recognition of parent misrepresentations - cannot be ignored. The fact that the English reports recognised the important role of parent representation in risk assessment is a significant step forward towards addressing intervention failures in such cases.

Representations such as these have an important role to play in determining the final outcome of intervention and whether the child becomes safer as a result. The interactive nature of a representation implies that it possesses the ability to reveal and conceal risks. A dysfunctional representation, then, skews risk assessments and, as these cases demonstrate, this potentially leads to child endangerment. The next question to ask is: how can child protection workers ascertain dysfunctional representation? This next section discusses the significance of the Pelka Report's finding that calls for professionals to rigorously interrogate parent representations.

\section{Social worker 'blindness'}

The far more important question to ask is, why would a professional accept parental versions of events? From a psychoanalytical perspective, Herman (2005) argues that parents tend to project their child 'self' onto their child as a means to either repair or relieve themselves of their own childhood trauma. In his article, Herman does not go as far as to suggest, even though this may be wholly possible, that the social worker has chosen the profession as a way of repairing his or her own childhood hurts and therefore may be 'blind' to the ongoing abuse of the client-parent in question. The projective identification of the parent onto the child as discussed by Herman (2005) is useful in explaining a particular kind of filicidal violence in which the parent-abuser projects onto the child the violence or trauma he or she experienced at the hands of the other partner. The following case is an example of such a dangerous and fatal projection.

At two years and seven months of age, Casper was constantly the object of his mother's anger. His mother, Elise, was angry with her former spouse (Casper's father) who threatened to kill her and was serving time in jail for assault. Elise often expressed to others that Casper reminded her of his father. She verbally abused him and physically punished him severely. The family worker who was in touch with Elise did not have a clear understanding of the family's history of violence. As such, in the days before Casper's death, the family worker refrained from contacting child protection because of the likelihood that Casper would be removed from Elise's care.

To argue that the family worker in Casper's case failed to neutralise the impending violence (in spite of the parent-client request for external assistance) as a result of his or her own childhood history and relationship with his or her own parents is at best speculative. From an interactionist perspective, it may be said that the lack of objective knowledge on the 
part of the family worker played a major role in Casper's death. Had the family worker had the benefit of knowing the family's history of violence, he or she might have thought differently of Elise's representation as the helpless mother. Similarly, in the Pelka and Connelly cases, the 'blindness' was critical to the children's safety where it related to not objectively 'seeing', or properly investigating, the children's injuries outside of their parents' representation of events. An interactionist approach challenges social workers to look beyond the facade or what is presented in front of them to consider the different interactions the parent has had, and what such impacts might have on the parent concerned and the safety of the child.

\section{Counteracting dysfunctional representation}

As evidenced by the cases, a parent demonstrating cooperation and compliance with professionals can mislead the authorities into thinking there are few risks of endangerment to the child. The English reports reveal the dangerousness of this representation if left unquestioned, particularly when there are obvious signs of injuries that were explained as 'accidental'. As argued above, social worker 'blindness' also contributes to the overall 'invisibility' of the child. Often, the police, rather than doctors, social workers or lawyers, have more accurate perceptions of the actual state of misrepresentation by the parents, and of the child's injuries. Jones (2014:36) points to the fact that, in Peter's case, the police were already investigating ongoing child abuse allegations, but their role was not mentioned in the Connelly Reports. How then can parental dysfunctional representation be addressed? The following sections discuss two components in counteracting dysfunctional representations. The first is identification and the second is training.

\section{Identification}

The Connelly Reports warned that child protection workers should be sceptical of parental accounts, which must be 'tested thoroughly against the facts' (2009b:68 [4.3]). The assessment of Peter's mother as 'cooperative' and 'caring' with an 'exceptionally active and “clumsy” toddler' (Connelly Reports 2008a:78 [6.12.28]) was erroneous from the start. This untested belief structured subsequent interpretation and understanding of events throughout the case. Similarly, Community Services in NSW made the flawed assumption that Ebony's situation was no different from her siblings, who were seen by caseworkers and reported to be healthy (Ebony Report 2009:16 [4.9]). The status of Ebony was thus left unverified by child protection workers.

Munro (1999) and Reder and Duncan (2000a) both emphasise that this is a common error that often results when a group of workers develop a fixed view about a case and become inaccessible to contrary information and observations. Additionally, professionals make 'selective interpretations', 'only registering that which confirmed their pre-formed view about the case and, in certain instances, these views appeared to become "pervasive beliefs" that organised all professional responses to the family' (Reder and Duncan 2000a:443; Connelly Reports 2008a:78 [6.12.29]). This process of reasoning appeared to have organised the responses in the Pelka and Ebony cases [Pelka Report 2013:70-1, 73; Ebony Report 2009:16). Both reports pointed out that because the siblings of Ebony and Daniel appeared well cared for, there was the assumption that Ebony and Daniel were no different. However, such assumptions were fundamentally flawed in those cases because the perceptions were not independently ascertained. 
Reder and Duncan (2000a; 1999:91) further postulate that parents often give authorities covert or overt warnings of their abuse of the child, which professionals needed to be to be able to translate, but in these cases they did not. They use the term 'disguised compliance' for this sort of behaviour exhibited by the parent. Disguised compliance is 'a process whereby parents defused professionals' attempts to take a more authoritative stance through preemptive acts of apparent cooperation' (Reder and Duncan 2000a:444). While the compliance may be temporary, this was just enough to keep caseworkers at arm's length and persuade them of their willingness to be more open (Connelly Reports 2008a:95-8). The potential for perpetrators' seemingly innocuous representations or warnings (of the abuse) to contain the 'masked' message (of impending violence to the child) is a serious consideration to which caseworkers should be sensitive (Reder and Duncan 2000b:130). Therefore, the first step towards counteracting such a representation is identifying a particular representation for further investigation.

The misleading representation of disguised compliance is theoretically grounded in Goffman's interpretation of the presentation of an individual in daily activities (Goffman 1990:17). Goffman (1990:9, 15-27; Denzin 1992:97) likens the individual to an actor who plays various roles on various stages before an audience, depending each time on what each stage demands. It is arguable that the audience these perpetrators were 'acting for' was the authorities to whom they feigned the role of the caring and compliant parent. The layered nature of such a representation is not, in other contexts, unusual. But in the particular contexts of filicide and fatal child abuse, it has the potential to hide risks of child endangerment, and manipulate authorities into adopting a different approach towards the parent and child. For example, in Peter's case, his mother's appearance of cooperation deflected child protection workers' focus from her abuse to Peter's behaviour (Connelly Reports 2008b:97). Had Peter's mother's representation been flagged for investigation, the circumstances of Peter's injuries and their lack of improvement may have been independently questioned by child protection workers. It is also possible that the injuries, if identified as a cause for concern, would have indicated that Peter was at risk of endangerment.

It appears unequivocal that parent perpetrators of abuse and neglect can reveal their violence towards the child through their representations, which structure their varying interactions with health and social professionals. The crux of effective intervention, then, is being able to identify precisely the warning signs, and to execute timely interventions. However, this is not simply said or done. As the Connelly Reports (2008b:59) point out, there also exist different perceptions of risk among the decision-making processes of intervening professionals. What is clear, though, is the need for a holistic approach, which considers an interaction of risk factors. For instance, the Pelka Report (2013:58-9) found that the paediatric assessment did not consider the possibility of abuse when presented with Daniel's weight loss, excessive appetite and behavioural difficulties. Such a lack of agreement among multi-agency professionals needs to be further addressed.

Identifying dysfunctional representation as a potential indicator of risk is the first step towards changing stereotypical assumptions about parent perpetrators of violence. The view held by the London Safeguarding Children Board (2010:343 [10.2]) that parent perpetrators often present as uncooperative, for example, is thus challenged when presented with the parents in these cases. This recognition has widespread implications for preventative strategies as it relates to child focus practices. 


\section{Training: The role of the caseworker}

The second proposal to counteracting dysfunctional representation is caseworker training. Specific training about the different 'facades' or representations that parents adopt might allow caseworker to better identify and flag further investigation. This is not without difficulties. How do we differentiate which representation is genuine and which is cause for concern? Taking Goffman's theory at its highest in favour of the actor, each representation is equally valid, even though the audience and platform changes. It is not for this author to provide a comprehensive review of child protection practice and training. This article merely suggests that specific training about representations can benefit the identification process and complement existing practice and training. Without a doubt, when caseworkers are constantly exposed to details of child abuse their capacity to make rational decisions can be affected (Morrison 1990; Rushton and Nathan 1996). The potential to baulk under pressure while performing the task of information gathering, an essential aspect of risk assessment (Rushton and Nathan 1996), can be fatal to the child.

As Rushton and Nathan (1996) also point out, child protection practice has, over time, adopted various theories and concepts to attempt to conceptualise the complex processes involved in risk assessment and child protection supervision. Rather than selecting one theory for practice, recognising the need for a convergence of theories is helpful to provide a far richer site for knowledge development (Tilbury et al 2007). Understanding that representation has a role to play in determining the nature and outcome of assessment and intervention is the first step to addressing the specific type of training needed for caseworkers.

\section{Scapegoating and implications for prevention}

Scapegoating is when a person is blamed for wrongdoings, mistakes or faults of others in the interests of expediency, and it happens when the failings or disowned aspects of a group are punished for them (Ruch et al 2014). As a mechanism to control inner chaos and gain control, power and allegiance (Ruch et al 2014), scapegoating is a powerful human processing dynamic that apportions and isolates blame. Girard (1986) theorises that scapegoating is performed to maintain social cohesion and order. In child protection practice, scapegoating is common but not without negative consequences (Munro 2011). The dismissal of Sharon Shoesmith, former head of children's services at Harengy Council (the suburb of North London in which the Connelly family resided at the time of Peter's death), following the death of Peter Connelly is a clear example (Jones 2014). Jones (2014) further points out the effect of scapegoating following the sacking of Shoesmith. Scapegoating 'destabilised a child protection system which had been finely tuned over 50 years since the death of Maria Colwell and the Colwell Inquiry in the early 1970s, albeit a system where burgeoning procedure manual had led to the clogging up of the engine as the oil of professional judgement and wisdom was drained from it' (2014:290). The ramifications of scapegoating are thus increased costs and workloads, increased pressure on social workers (Jones 2014); and, as argued, more pressure potentially leads to fatal judgment in risk assessment.

Ruch et al (2014) argue that the lack of trust generated by scapegoating means that the vicious cycle - starting from, lack of visibility of the children, faulty parental representations, interventionist failures to adequately neutralise risks early, to a child's death, then scapegoating, which leads to a climate of distrust — is a bleak picture for our children's future. Navigating the tension between safeguarding the intactness of families whose children may not need protecting by the state and those that require protection is a delicate exercise. There 
is no easy solution, especially not one that only relies on training and identification of dysfunctional representations. While providing reflective spaces (Munro 2011; Ruch et al 2014) is one way of addressing the negative impact of scapegoating, society needs to also build on community-based approaches that focus strengthening the resilience of families. Projects such as the Pathways to Prevention Project (Homel et al 2006) is an example. The positive side of early intervention in an approach such as Pathways to Prevention is that it builds attachment and interconnectedness between parent, child and support agencies. For vulnerable families, this may be the type of support that makes the difference between a child's life and death.

In terms of prevention, alternatively, it may also be desirable to strengthen existing policies grounded in a community prevention approach (Sim 2012:472). Such an approach could involve other persons (who interact regularly with the parent or child) who may be able to provide a different perspective on the parent representation or their version of events in question. This can assist the parent to seek outside support and downplay their need to manipulate the authorities using false representations. However, this is not without problems. For families such as Daniel Pelka's, whose residences are transient, constant relocations mean that maintaining a continuous level of community support and depth of interaction can be difficult (Sim 2012:473).

Going back to Dingwall's quote at the beginning of this article, while the system is far from perfect, there will be errors and deaths as trade-offs for the majority of children kept safe. Nevertheless, an interactionist framework geared towards a holistic understanding of the parent as a social actor and the nature of parental representations may go some way towards minimising these trade-offs. In particular, de-emphasising scapegoating practice and strengthening community-based early intervention and prevention approaches, along with the appropriate caseworker training, can provide the foundation for an actual preventative strategy, rather than a model of child protection based on crisis intervention.

\section{Conclusion}

There are lessons to be learnt from the deaths of these three children. Representation is a significant component governing interactions between the family and the state. Parent representations circumventing risk identification such as that of disguised compliance may elude detection and possibly circumvent the law. Child visibility is a central tenet in risk assessment and intervention coupled with interagency support and 'sound principles and procedures for collaborative working' (Laming Report 2009).

In Australia, the NSW Ombudsman too, in 2007, has identified a greater need for multiagency cooperation (Ebony Report 2009:53). Inter-agency support and effective communication are thus essential pillars for thorough child protection operations. The Pelka Report (2013) further identifies a growing need, operationally, to adopt a holistic approach rather than an incident-specific one, which does not take into consideration patterns of behaviour and family lifestyle. The Pelka Report (2013) critically stresses the dangerousness for professionals in making decisions that are based on other people's views without first ascertaining the objective facts or evidence for themselves. This puts the burden on child protection workers to operate from an informed position when making assessments and taking decisions on intervention in relation to the child in question.

The aftermaths of the children's deaths saw the media engaged in a blame game (Butler 2014; Malone 2013; Smith 2009; Salusinszky 2009; Reder et al 1993:2-3, 121) largely 
targeting social services. In terms of prevention, this has achieved little. As Reder et al (1993:3) caution, such a response does not inform how things can go wrong. Instead, considering how the events could be understood within complex relationships and interactions between families and child protection and health professionals is more constructive in terms of offering better protection to children at risk (Reder et al 1993:136). Additionally, misleading and false parent representation can potentially impact outcomes and have ramifications for child safety if not identified early and objectively assessed.

This article has attempted to bring the focus back to the issue of prevention. It examined the findings of the child death inquiries into three fatal child abuse cases. It identified two critical indicators of risk, the invisibility of the child and untimely recognition of misleading parent representation, arguing that they can signal the possibility of dysfunctional intervention. We can take away from this that, first, children's visibility is critical to their safety; second, parent representations in the context of potential child harm can be dangerous and risky because they conceal the seriousness of the risks of endangerment from the authorities. Parent representations must be challenged against objective evidence in conjunction with a consideration of the interaction of other risk factors. While this may be a small step, it could make all the difference between timely intervention and preventable death.

\section{Cases}

Goode v Goode (2006) 36 Fam LR 422; (2006) 93-286

$R v B W \& S W$ (No 3) [2009] NSWSC 1043 (2 October 2009)

$R v$ Mariusz Krezolek and Magdelena Luczak Birmingham Crown Court (2 August 2013)

\section{References}

Anthony A (2009) 'Baby P: Born into a Nightmare of Abuse, Violence and Despair, He Never Stood a Chance', The Guardian (online), 16 August $2009<$ http://www.theguardian.com/society/2009/ aug/16/baby-p-family>

Australian Institute of Family Studies (2014) Child Deaths from Abuse and Neglect $<$ http://www.aifs.gov.au/cfca/pubs/factsheets/a142119/>

Butler P (2014) 'The Sun's Poisonous Blame Game after Baby P Still Haunts Social Work', The Guardian (online), 15 July 2014 <http://www.theguardian.com/society/2014/jul/15/baby-p-bookexamines-toxic-impact-of-sun>

Campbell D, Jones S and Brindle D (2008) '50 Injuries, 60 Visits — Failures that Led to the Death of Baby P', The Guardian (online), 12 November $2008<\mathrm{http} / /$ www.theguardian.com/society/ 2008/nov/12/baby-p-child-protection-haringey>

Cashmore J, Parkinson P, Weston R, Patulny R, Redmond G, Qu L, Baxter J, Rajkovic M, Sitek T and Katz I (2010) Shared Care Parenting Arrangements since the 2006 Family Law Reforms: Report to the Australian Government Attorney-General's Department, Social Policy Research Centre, University of New South Wales

Cooper A and Whittaker A (2014) 'History as Tragedy, Never as Farce: Tracing the Long Cultural Narrative of Child Protection in England', Journal of Social Work Practice 28(3), 251-66 
Corby B (2000) Child Abuse: Towards a Knowledge Base, Open University Press

Cummings L (2009) 'Ebony’s Mum Sentenced to Life', The Courier Mail (online), 2 October 2009 $<$ http://www.couriermail.com.au/news/ebonys-mum-sentenced-to-life/story-e6freon6$1225782044779>$

D’Cruz H (2001) 'The Fractured Lens: Methodology in Perspective' in H Byrne-Armstrong, J Higgs and D Horsfall (eds), Critical Moments in Qualitative Research, Butterworth-Heinemann

D’Cruz H (2002) 'Constructing the Identities of "Responsible Mothers, Invisible Men” in Child Protection Practice’, Sociological Research Online 7(1) <http://www.socresonline.org.uk/7/1/ dcruz/html>

D’Cruz H (2004) Constructing Meanings and Identities in Child Protection Practice, Tertiary Press

Denzin N (1992) Symbolic Interactionism and Cultural Studies: The Politics of Interpretation, Blackwell

Dingwall R (1986) 'The Jasmine Beckford Affair’, The Modern Law Review 49, 489-507

Dolan A (2013) 'Boy, Four, "Whose Parents Starved Him to Death Suffered Incomprehensible Cruelty and Looked Like Concentration Camp Victim”, Daily Mail Australia (online), 4 June 2013 $<$ http://www.dailymail.co.uk/news/article-2335250/Daniel-Pelka-Boy-4-parents-starved-deathsuffered-incomprehensible-cruelty.html>

Donzelot J (1979) The Policing of Families, Pantheon Books

Girard R (1986) The Scapegoat, The John Hopkins University Press

Goffman E (1959, 1990 ed) The Presentation of Self in Everyday Life, Penguin

Goodwin S and Finkelstein J (2005) The Sociological Bent: Inside Metro Culture, Thomson

Haringey Local Safeguarding Children Board (2008a) Serious Case Review 'Child A', Department of Education ('Connelly Reports')

Haringey Local Safeguarding Children Board (2008b) Serious Case Review 'Child A': Executive Summary, Department of Education ('Connelly Reports')

Harvey A and Henderson F (2014) 'Reflective Supervision for Child Protection Practice - Reaching Beneath the Surface', Journal of Social Work Practice 28(3), 343-56

Herman J (2005) 'Psychoanalytic Insight-Oriented Parent Counseling Based on Concepts of Protective Identification and Reparative Repetition: An Object Relations Perspective', Journal of Infant, Child and Adolescent Psychotherapy 4(4), 442-56

Higgins D, Bromfield L, Richardson N, Holzer P and Berlyn C (2009) Mandatory Reporting of Child Abuse and Neglect, National Child Protection Clearinghouse Resource Sheet No 3, Australian Institute of Family Studies

Johnson CH (2005) Come with Daddy: Child Murder-suicide after Family Breakdown, University of Western Australia Press

Jones A (2009) Haringey Local Safeguarding Children Board Serious Case Review 'Child A', Department of Education

Jones R (2014) The Story of Baby P: Setting the Record Straight, Policy Press 
Jones S (2008) 'Sixty Missed Chances to Save Baby "Used as a Punchbag”', The Guardian (online), 12 November 2008 <http://www.theguardian.com/society/2008/nov/12/child-protection-crime-baby-p>

Kaspiew R (2005) 'Violence in Contested Children’s Cases: An Empirical Exploration', Australian Journal of Family Law 19(2), 112-43

Keene N (2009) 'Mother Who Starved Young Daughter Ebony to Death Showed no Sadness or Anger', The Daily Telegraph (online), 7 August $2009<$ http://www.dailytelegraph.com.au/news/nsw/motherwho-starved-young-daughter-ebony-to-death-showed-no-sadness-or-anger/story-e6freuzi$1225758736092>$

Kent P (2009) 'One Long, Silent Scream — Ebony's True Death Exposed', The Daily Telegraph (online), 31 July 2009 <http://www.dailytelegraph.com.au/one-long-silent-scream-ebonys-true-deathexposed/story-e6freuy9-1225756563609>

Laming L (2009) The Protection of Children in England: A Progress Report, The Stationary Office

Lock R and Fraser N (2013) Coventry Safeguarding Children Board Serious Case Review Re Daniel Pelka: Overview Report, Coventry LSCB ('Pelka Report')

London Safeguarding Children Board (2010) London Child Protection Procedures, $4^{\text {th }}$ ed

McIntosh J and Chisholm R (2008) 'Cautionary Notes on the Shared Care of Children in Conflicted Parental Separation’, Journal of Family Studies 14(1), 37-52

Malone C (2013) 'Daniel Pelka's Parents Aren’t the Only Ones to Blame - So Why is No One Accountable', Mirror (online), 4 August $2013<$ http://www.mirror.co.uk/news/uk-news/carole-malonedaniel-pelkas-parents-2121112>

Morgan B and Yeung K (2009) An Introduction to Law and Regulation, Cambridge University Press

Morris S (2013) 'Daniel Pelka: Professionals Failed “Invisible” Murdered Boy, Report Says', The Guardian (online), 17 September 2013 <http://www.theguardian.com/society/2013/sep/17/ professionals-failed-report-daniel-pelka>

Munro E (1996) ‘Avoidable and Unavoidable Mistakes in Child Protection Work’, British Journal of Social Work 26, 793-808

Munro E (2005) 'A Systems Approach to Investigating Child Abuse Deaths’, British Journal of Social Work 35, 531-46

Munro E (2011) The Munro Review of Child Protection: Final Report - A Child-Centred System, CM 8062, The Stationary Office

NSW Ombudsman (2009) The Death of Ebony: The Need for an Effective Interagency Response to Children at Risk <https://www.ombo.nsw.gov.au/_data/assets/pdf_file/0012/3360/Special-ReportDeath-of-Ebony-Oct-2009.pdf>

Parkinson P (2013) 'Violence, Abuse and the Limits of Shared Parental Responsibility', Family Matters 92, 7-17

Pollock G (1988) Vision and Difference, Routledge

Reder P and Duncan S (2000a) 'A Required Mind-Set for Child Protection Practice: Comments on Munro (1999)', Child Abuse \& Neglect 24(4), 443-5

Reder P and Duncan S (2000b) Lost Innocents: A Follow-up Study of Fatal Child Abuse, Routledge 
Reder P, Duncan S and Gray M (1993) Beyond Blame: Child Abuse Tragedies Revisited, Routledge

Rhoades H (2008) 'The Dangers of Shared Care Legislation: Why Australia Needs (Yet More) Family Law Reform', Federal Law Review 36, 279-99

Rose N (1987) 'Beyond the Public/Private Division: Law, Power and Family', Journal of Law and Society 14(1) 61-76

Ruch G, Lees A and Prichard J (2014) 'Getting Beneath the Surface: Scapegoating and the Systems Approach in a Post-Munro World', Journal of Social Work Practice 28(3), 313-27

Rushton A and Nathan J (1996) 'The Supervision of Child Protection Work', British Journal of Social Work 26, 357-74

Ryan S (2009) 'Behind Bars for Starving Ebony, Father Wins Access to Her Sisters', Newcastle Herald (online), 14 August $2013<$ http://www.theherald.com.au/story/446608/behind-bars-for-starving-ebonyfather-wins-access-to-her-sisters/>

Salusinszky I (2009) ‘Authorities Left Ebony to Starve’, The Courier Mail (online), 7 October 2009 $<$ http://www.couriermail.com.au/news/authorities-left-ebony-to-starve/story-e6freon6-

1225783623135>

Shengold L (1999) Soul Murder Revisited, Yale University Press

Silva K (2014) 'Grandparents' Campaign to Change Abuse Reporting Laws Reach MP Meeting Milestone’, Brisbane Times (online), 3 August 2014 <http://m.brisbanetimes.com.au/queensland/ grandparents-campaign-to-change-abuse-reporting-laws-reach-mp-meeting-milestone-20140801zzlwq.html>

Sim J (2012) 'Bridging the Gap: Thinking Beyond the State in Child Protection', Current Issues in Criminal Justice 23(3), 469-75

Smith S (2009) 'Starved Girl: Agencies “To Blame”', The Sydney Morning Herald (online), 6 October 2009 <http://www.smh.com.au/national/starved-girl-agencies-to-blame-20091006-gkdr.html>

Tilbury C, Osmond J, Wilson S and Clark J (2007) Good Practice in Child Protection, Pearson Education

Wilczynski A (1995) 'Risk Factors for Parental Child Homicide: Results of an English Study’, Current Issues in Criminal Justice 7(2), 193-222 